\title{
PREPARATION OF NEW PHYSICS TEACHERS FROM VARIOUS PERSPECTIVES
}

\author{
Peter Demkanin \\ Comenius University in Bratislava, Slovakia
}

There is no doubt, that preparation of new teachers significantly influences many aspects of education. Most of us, readers of this Journal, are involved in preparation of new science teachers. My group focuses on physics teachers for secondary school level and this is the main perspective of this reflection.

When we talk about physics teacher, we usually imagine formal education - education at schools with prescribed goals. Of course, many of us feel that we need well educated educators also for informal and unformal education - for science clubs, for preparation of good material for our children and teens for TV and web. I have in mind both groups of physics educators here. By the way, recent research proved that the main source of science related knowledge of teens in my country after school is TV, much more than web, parents or printed media (Demkanin \& Chalupkova, 2011).

Science education from the perspective of majority of science teachers (in many countries) is quite stable (Petty, 2009). But changes in society are relatively fast, and this is true also in the aspects closely related to the science education. Information is easily accessible (generally, not from the perspective of pupils), the speed of communication has risen significantly; our pupils use the equipment, which was available only in some top laboratories some years ago. Science education should also reflect great changes of society, like globalisation, climatic changes, terrorism, boom of automotive and building industry; and, in many countries, also radical political changes and economic crisis. On the other hand, the processes of the mind of our children are still the same. We, people involved in pre-service teacher training, should be aware of the stability of the science education (from the perspective of teachers) and sensitively take the changes into account, and also little bit foresee the future. Within this reality we should apply the pedagogical and psychological theories to current situation and enrich them. Here is a large field for our investigation.

Many of us work with transformative model of the knowledge base for teaching and with the concept of pedagogical content knowledge (PCK) (Magnusson, Krajcik \& Borko, 1999). We highlight five components of PCK: orientation toward science teaching; knowledge (and beliefs) about science curriculum; knowledge (and beliefs) about students' understanding of science topics; knowledge (and beliefs) about assessment in science; and knowledge (and beliefs) about instructional strategies for teaching science. Let's look at them from the perspective of pre-service teacher trainer.

What orientation toward teaching do we develop? Do our teachers reflect the main goal of science education - to raise scientific literacy of people? Definition of science literacy can help us. "Science literacy is an individual's scientific knowledge and use of that knowledge to identify questions, to acquire new knowledge, to explain scientific phenomena, and to draw evidence-based conclusions about science-related issues, understanding of the characteristic features of science as a form of human knowledge and enquiry, awareness of how science and technology shape our material, intellectual, and cultural environments, and willingness to engage in science-related issues, and with the issues of science, as a reflective citizen" (OECD, 2009, p.14). Many of us clearly see relatively large group of teachers, who still prefer transmissive teaching to inquiry based teaching. From our perspective, bearing in mind raising scientific literacy of pupils, this is inadmissible in pre-service teacher training. It has a high priority to change the attitudes of our physics teachers towards evidence based teaching and to inquiry based scaffold teaching/learning. In this area extensive research has been done and now we are at the stage to reach a critical mass of teachers consciously using the upto-date methods in their daily work.

Within the process of preparation of new teachers we are also making a base for transformation of curriculum. What is the direction in which we would like to steer and transform science curriculum? My group divided goals (and content) of physics education to: A. goals (and content) related to attitudes of society towards science; B. goals (and content) related to methods of science; C. goals (and content) related to pieces of knowledge. Last part we divide to C1.pieces of knowledge for development of scientific methods and attitudes towards science; $C 2$.pieces of knowledge related to the quality of living and general scientific culture. To make it clearer we have formulated leading questions: Why do we need science? (goal 
A); How do we know that the nature "works" in the way we think it does? (goal B); How does the nature work? And how could we use the knowledge in the technology? (goal C). This list together with the leading questions does help our students, future physics teachers, to look at the sense of the content they will teach later at their schools. How to select the pieces of information to set a curriculum at the national level, how at school level, how at the level of textbook writer? How to transform it to a perfect system? Answers to such questions we should base on results of well-planned research.

The next part of PCK is the knowledge of students' understanding of science topics. Here we, in general, have done a great deal of work. Many researchers and practitioners are working in this field. Some of us are working mainly empirically. We are observing, testing, questioning, and interviewing our pupils. Let's stop for a minute and take the question: What is "force"? Dear reader, please, for a moment look at the question from the perspective of physics teacher; and then from the perspective of a 12 year old pupil. See that? There is a great difference. In the area of students' understanding of science topics useful models and ideas bring well developed cognitive psychology. What about using such models in our research? And what about looking at the problems of colleagues working in science education at primary schools (Lamanauskas, 2012)?

Looking at students, future physics teachers, the next part of PCK, assessment in science education is quite a big problem to be solved. We can use well working strategies for development of the ability of our students to ask, to formulate a question. But we should also teach what aspects of knowledge are to be assessed and how to weigh the aspects for summative assessment. In educational systems with welldeveloped external assessment a teacher could feel relatively safe. Without external assessment this area is very demanding, especially for a new teacher.

The last part of the PCK is called "instructional strategies". Instructional strategies are described in good detail even in some textbooks, e.g. in (Petty, 2009).

To enrich pre-service teacher training and to make it up-to-date we are doing research in the areas mentioned above, and also in many other. To grasp the education as a whole, we should simplify the complexity of the topic, usually by making models. We use two basic types of models. In one of them we study individuals; the elements of the model are parameters of the individual. We are modelling interactions such as: teacher - pedagogical field; teacher-student; student-student; student - environment. We often use methods like constructing grounded theory (Charmaz, 2006), we don't state hypothesis, just a field of interest. In the other group are models in which we study large groups of individuals. We use statistics, making averages and looking for general trends. We are testing hypothesis. And then, on Meta level we are systematising the results and improving our work. So, let's go back to teaching, researching, writing, let us go to our daily important work.

\section{References}

Demkanin, P., \& Chalupková, S. (2011). Students' hobbies as a context for physics teaching. Scientia in Educatione, $2,15-22$.

Charmaz, K. (2006). Constructing Grounded Theory: A Practical Guide Through Qualitative Analysis. Thousand Oaks, CA: Sage Publications

Lamanauskas, V. (2012). A problem of Science Literacy Encountered by Primary School Teachers and Learners. Journal of Baltic Science Education, 11 (4), 300-301.

Magnusson, S., Krajcik, J., \& Borko, H. (1999). Nature, sources and development of PCK for Science Teaching. In: Gress-Newsome, J., \& Lederman, N.: Examining Pedagogical Content Knowledge. Amsterdam, Kluwer Academic Press, pp. 95-132.

OECD (2009). PISA 2009. Assessment Framework. OECD, pp. 14.

Petty, G. (2009). Evidence Based Teaching. Cheltenham, Nelson Thornes.

Received: February 15, 2013

Accepted: February 25, 2013

Peter Demkanin $\quad$ PhD. in Physics Education, Associate Professor, Comenius University, Faculty of Mathematics, Physics and Informatics, Department of Physics Education, Mlynska dolina F1, 84248 Bratislava, Slovakia. E-mail:demkanin@fmph.uniba.sk 